\title{
An osteopontin promoter polymorphism is associated with aggressiveness in breast cancer
}

\author{
DIVYA RAMCHANDANI and GEORG F. WEBER \\ University of Cincinnati Academic Health Center, College of Pharmacy, Cincinnati, OH 45267-0004, USA
}

Received May 29, 2013; Accepted July 1, 2013

DOI: $10.3892 /$ or.2013.2632

\begin{abstract}
Metastasis-related genes are deregulated in cancer by aberrant expression or splicing. Here, we analyzed polymorphic sites in the osteopontin promoter as potential contributors to aberrant expression in breast cancers. This study comprised 241 breast cancer specimens, for which DNA from normal surrounding tissue was available for 111, and 65 healthy breast samples. The polymorphic site in position -443 of the promoter was associated with tumor grade. As expected, there was no association between promoter single nucleotide polymorphisms (SNPs) and tumor stage or in situ carcinoma versus cancer, as stage and early transformation are determined by the sampling time more than by tumor genetics. In a subset of samples, osteopontin RNA expression levels had previously been obtained. The allelic distribution in positions -443 and -1748 was distinct between high and low expressors, confirming the importance of promoter SNPs. These two sites also form a haplotype. Osteopontin expression has been associated with breast cancer progression, regardless of the histological subtype of the cancer. Remarkably, the polymorphic site at -443 , but not -1748 or -1776 , showed differences between ER-positive and ER-negative breast cancers and between PR-positive and PR-negative breast cancers, but there was no association with HER2 status. In five cases, the genotype of the tumor was different from the genotype of the host, implying the possibility of somatic mutations in the osteopontin promoter that may affect expression. Our results corroborate that the osteopontin promoter SNPs -443 (rs11730582) and -1748 (rs2728127) are important for gene expression and breast cancer aggressiveness.
\end{abstract}

\section{Introduction}

Cancer initiation commonly occurs when the coding region of a proto-oncogene is mutated to induce a gain of function of

Correspondence to: Dr Georg F. Weber, College of Pharmacy, University of Cincinnati, 3225 Eden Avenue, Cincinnati, OH 45267-0004, USA

E-mail: georg.weber@uc.edu

Key words: cancer progression, polymorphism, promoter, gene expression the resulting gene product, such that it is excessively active, or when the coding region of a tumor-suppressor gene suffers a mutation that inactivates the resulting gene product. In either case, the pathophysiologic consequence is excessive cell cycle progression or defective programmed cell death. Cancer progression and metastasis are also genetically programmed. However, whereas mutations in the coding regions of critical genes underlie early transformation, metastasis gene products are typically not mutated in cancer. We previously demonstrated that aberrant expression or splicing of metastasis-related genes underlie tumor progression $(1,2)$.

Osteopontin is a metastasis-related gene that contributes to the progression of over 30 forms of cancer (3-5). Aberrant splicing of osteopontin in cancers has been accounted for by our identification of the variant form osteopontin-c, which is selectively expressed in cancer cells but is absent from non-transformed cells (6-8). Osteopontin-c supports anchorage-independent survival and expansion, which are essential components of tumor dissemination (9).

Although osteopontin (encoded by the gene spp1) has been known to be produced at elevated levels by cancer cells (10), the molecular underpinning for its aberrant expression in cancer is incompletely accounted for. Osteopontin may be induced as a downstream signal transduction target of proto-oncogenic growth factors (11) or secondary to gain-offunction events in transforming signaling pathways (12-14). In either case, the binding of cognate transcription factors to spp1 promoter regions is causative for the upregulated expression. This opens the possibility that mutations or polymorphisms in the promoter of the sppl gene (Fig. 1) may predispose to various levels of expression after transformation, and hence to various levels of tumor aggressiveness. Here, we investigated this hypothesis for breast cancer.

\section{Materials and methods}

Patients. There were 4 sources of specimens. DNA from breast cancer patients and healthy controls was obtained from the Division of Human Genetics at The Ohio State University (50 breast cancers, 50 untransformed surrounding tissues, 50 healthy breasts). From tumors previously analyzed for osteopontin RNA expression (6), DNA was obtained by phenol/chloroform extraction (23 breast cancers, 11 surrounding tissues, 15 healthy breasts). DNA from breast cancers and surrounding tissues was purchased from Bioserve 
A

\begin{tabular}{|c|c|}
\hline-2079 & 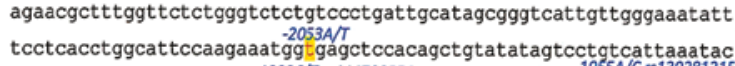 \\
\hline-2015 & 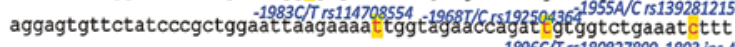 \\
\hline-1951 & $\begin{array}{l}1896 \mathrm{C} / \mathrm{r} s 1808278991893 \text { ins } \mathrm{A} \\
\text { tttcagaaatgctgccatcgtgtggcactgcggagctatgaccagaagagtcctgtaaagggtc }\end{array}$ \\
\hline-1887 & gtatggttcatctcaagatggctgggetccagcataatct \\
\hline-1823 & 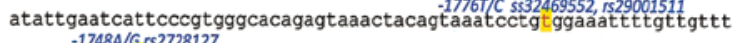 \\
\hline-1759 & ctccactaaattgacaacatgacacgcttatgcgggtatgtttaa \\
\hline-1695 & aggaaaaaatagtttttagaagcagaaaaaagaagtctattttgcaactttataatctgtgtg \\
\hline-1631 & Égcttattacctacaaac \\
\hline-1567 & aatg \\
\hline-1503 & tagctat \\
\hline-1439 & ttaaaagtaatatttggcaaaaggaagctgacactttaggactaataaaaaccacaattacttt \\
\hline-1375 & tgcagcaacctaataataaataggaccatttattttcatctcaattacacacaagtct taaca \\
\hline-1311 & ataaaggtgtaaggtaaataaatagtgcaatctgcatttcacaactgagaaacaaatgaagata \\
\hline-1247 & agtaatctcaaggcaatattaaatattttaaaaggacccagagctctgctatccctgaattctg \\
\hline-1183 & $\begin{array}{c}\text { ctctaatattcggactttccctgtaattttctttcattcagacaccttttaaatacctagtaaa } \\
-1100 \mathrm{~A} / \mathrm{rrs}_{5} 59641329\end{array}$ \\
\hline-1119 & $\begin{array}{l}\text { ttaaaaatgtttttctttttaagtggcctactttacatacct } \\
\text { ttalis }\end{array}$ \\
\hline-1055 & $\begin{array}{l}\text { rs3891314 } \\
\text { gaaaaaaagatgattccaaaatcgaatctgttcctttagaaatgtgcaaa } \\
\text {-956C/T rs } 190538514\end{array}$ \\
\hline-991 & atttccttattgatgcatacaatttaaagatcttacgtctactctcattttaataacctgttct \\
\hline-927 & tttaaaggacattacaattcgtgactgcctgcccetcttaaaaatttcataatagttaacacac \\
\hline-863 & atatagtccttaagatacgcagagcatttgcatctaatatgtgctaagcattgctagtttaaca \\
\hline-799 & tactaat tcatttaaacccctcaaaaaccccatgacctaggtaatagtattgcatttcatggat \\
\hline-735 & $\begin{array}{l}\text { gagggaacaaggataggtaggctgggcgatttgcccaaggttgcacaggtcag } \\
-670 \mathrm{~A} / 6 \text { r } 5183186314-655 \mathrm{G} / \mathrm{T}\end{array}$ \\
\hline & $\operatorname{cgg}$ \\
\hline-607 & cagaaactgct \\
\hline-543 & $\operatorname{ttc}$ \\
\hline-479 & tgaacaat \\
\hline-415 & t tggctct tcaataagtacaatcatacaggcaagag \\
\hline-35 & $\begin{array}{l}\text { aáááá } \\
6 \\
\text { catgggai }\end{array}$ \\
\hline 87 & atgeccatccegtac \\
\hline
\end{tabular}

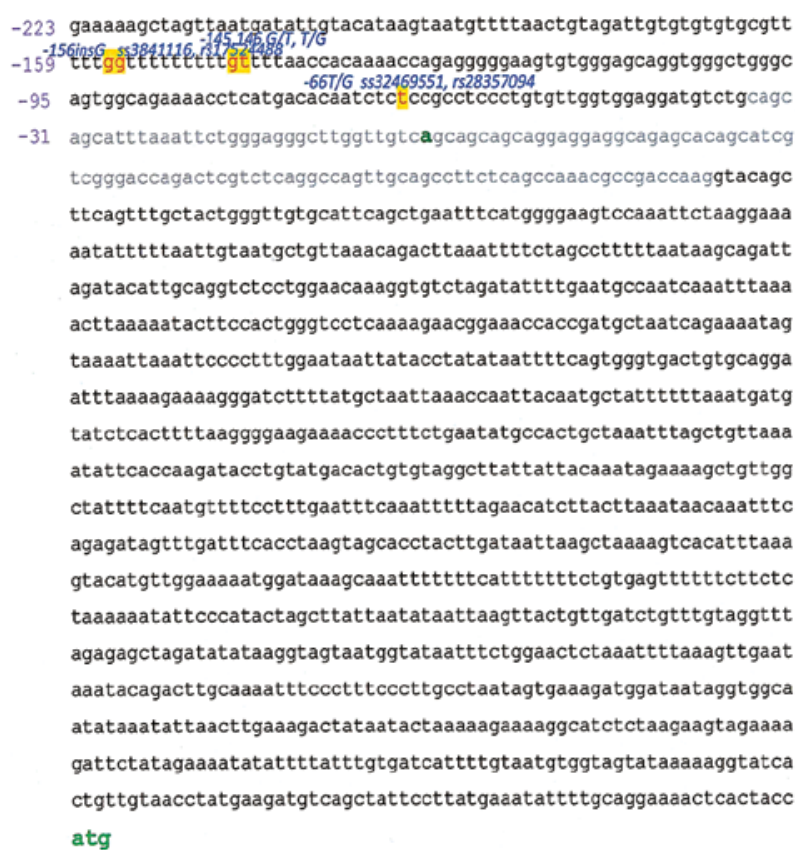

-223 gaaaaagctagttaatgatat tgtacataagtaatgttttaactgtagattgtgtgtgtgcgtt

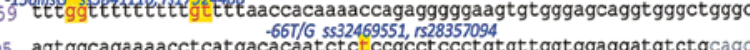

agcatt taaattctgggagggct tggttgtcagcagcagcaggaggaggcagagcacagcatc aatatttttaattgtaatgctgttaaacagacttaaattttctagcctttttaataagcagatt agatacattgcaggtctcctggaacaaaggtgtctagatattttgaatgccaatcaaatttaaa

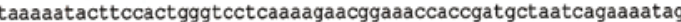
tatctcacttttaaggggaagaaaaccetttctgaatatgccactgctaaatttagctgttaaa atattcaccaagatacctgtatgacactgtgtaggcttattattacaaatagaaagetgttgg ctattttcaatgttttcctttgaatttcaaatttttagaacatcttacttaaataacaaatttc gtacatgttggaaaaatggataaagcaaattttttcatttttttctgtgagttttttcttctc taaaaatattcccatactagcttattaatataattaaģttactgttgatctgtttgtaggttt agagagctagatatataaggtagtaatggtataatttctggaactctaaattttaaagttgaat aaatacagact tgcaaaatttccctttccettgcctaatagtgaaagatggataataggtggca (a)ctaagagtagaaa ctgttgtaacctatgaagatgtcagctattccttatgaaatattttgcaggaaactcactacc $\operatorname{atg}$

Figure 1. Spp1 polymorphisms. (A) Promoter. The sequence is derived from NW_001838915.1 (whole genome shotgun sequence) and NT_016354.19 (genomic contig) (the 160 bases proximal to the transcription start site are also confirmed by GenBank nos. NM_001040058.1, NM_001040060 and NM_000582; of note, the GenBank sequences S78410.1 and D14813.1 contain a 60 nucleotide gap which is likely a cloning artifact). The silent exon 1 is grey. The 'A' that starts the conventional numbering of the promoter sequence is displayed in bold green font, as is the downstream ATG start site. The literature has identified 12 polymorphic sites (red letters on yellow background) in the spp1 promoter, of which 6 have rs or ss numbers (positions -66, -156, -443, -616, -1748, -1776) $(22,15,26,27,16)$. Additional polymorphic sites have been reported, and comprise -145/-146 (28), -302 (28), -593 (29), -655 (30), -1282 (31), -1625 (31) and -2053 (15). With the exception of one insertion/deletion polymorphism at position -156, all are single nucleotide exchanges. The position and nature of the polymorphism is indicated above each site in blue.

(86 tumors and 50 untransformed surrounding tissues) and from Origene ( 82 tumors). The total number of samples was 241 breast cancers, 111 surrounding tissues and 65 healthy breast specimens.

DNA genotyping. Genotyping was carried out using ABI PRISM 7900HT sequence detection system after performing polymerase chain reaction (PCR) on the DNA samples. The PCR was performed as directed by the ABI protocol for the TaqMan SNP genotyping assays using TaqMan Universal PCR master mix, primer and TaqMan probe (VIC/FAM) dye mix, and $5 \mathrm{ng} / \mu \mathrm{l}$ genomic DNA sample. The total reaction volume was $5 \mu$ l. Then, post-PCR plate reads were performed using the sequence detection system instrumentation to identify the distinct alleles according to their fluorescent signals. One probe set tested the spp1 polymorphic promoter sites -66 (rs28357094), -443 (rs11730582), -1748 (rs2728127) and -1776 (rs29001511). We also set out to investigate non-synonymous DNA sequence variations in the coding region. The available probes for this comprised the positions 305 (rs11544546), 367 (rs11544549), 794 (rs7435825) and 1025 (rs4660) and were all included in the present study.
$R N A$ and real-time RT-PCR. Specimens of human breast tumors, non-transformed surrounding tissue, as well as healthy breast tissue (obtained from reduction mammoplasties) were provided by the tissue procurement facility of the University of Cincinnati Medical Center/Children's Hospital (6). Total RNA was extracted from specimens using TRIzol reagent (Invitrogen Life Technologies). Total RNA was used for cDNA synthesis by reverse transcription with Superscript II (Invitrogen Life Technologies) according to the manufacturer's protocol in a total volume of $20 \mu 1$.

All PCR reactions were performed on a Smart Cycler (Cepheid, Sunnyvale, CA, USA) using SYBR-Green detection format. cDNA $(0.5 \mu \mathrm{l})$ was added to each PCR reaction in a total volume of $25 \mu \mathrm{l}$ using the standard Invitrogen Life Technologies PCR buffer system with optimized concentrations of $\mathrm{MgCl}_{2}$. For each experiment a no-template reaction and cDNA from the reference cell line MDA-MB-435 were included as negative and positive controls. The conditions for PCR were a $94^{\circ} \mathrm{C}$ denaturation for $120 \mathrm{sec}$ followed by 40 cycles of: $94^{\circ} \mathrm{C}$ melting for $15 \mathrm{sec}$, a primer set specific annealing temperature for $30 \mathrm{sec}(6)$, extension at $72^{\circ} \mathrm{C}$ for $30 \mathrm{sec}$, and ending with a melting curve program $\left(60-95^{\circ} \mathrm{C}\right.$ with a heating rate of $0.2^{\circ} \mathrm{C}$ 


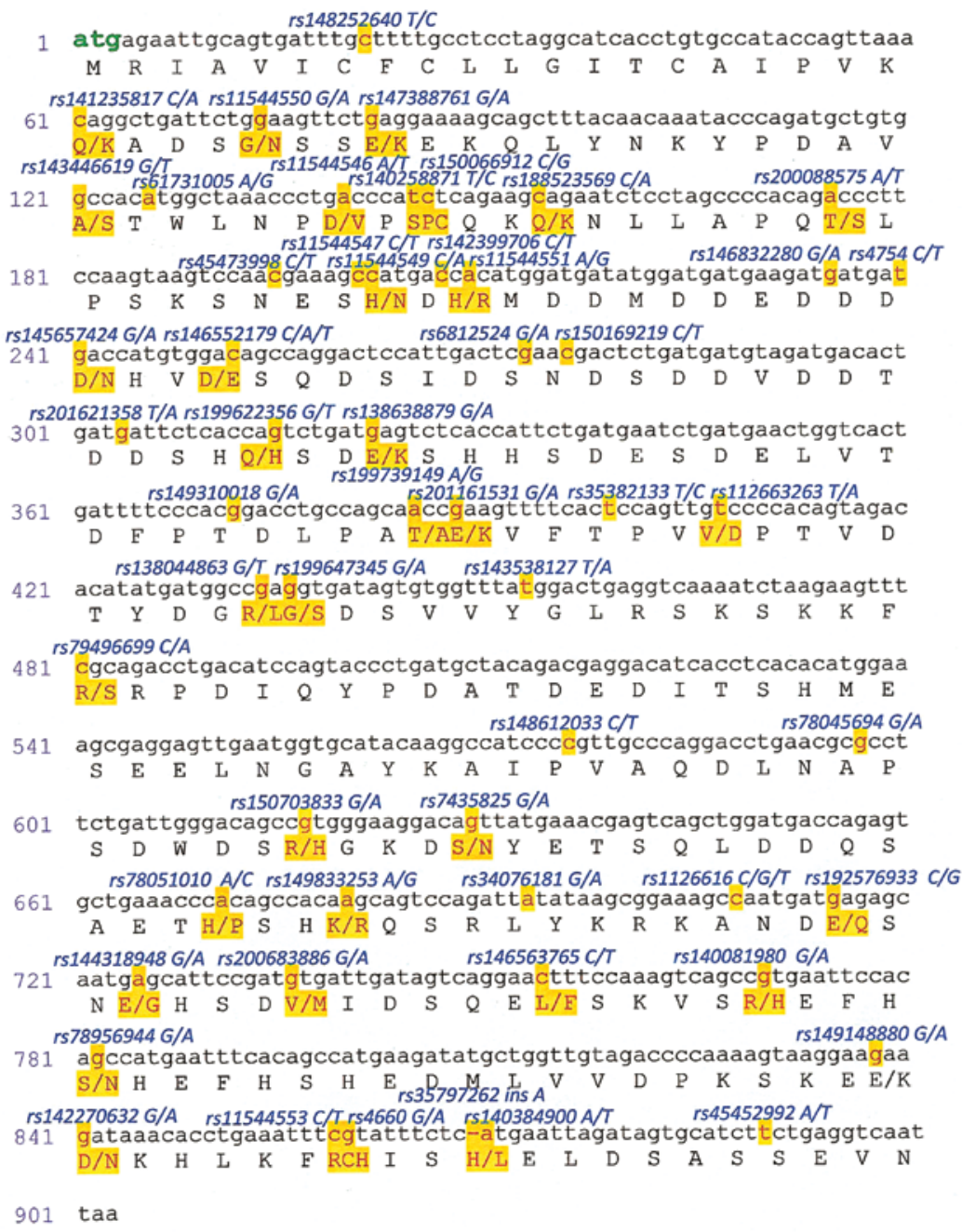

Figure 1. Continued. (B) Coding sequence. The polymorphisms with assigned rs numbers are identified in the NCBI SNP database. The protein sequence is shown under the nucleotide sequence, and for non-synonymous base changes the amino acid changes are depicted in red letters on yellow background. The position and nature of the polymorphism is indicated above each site in blue.

and a continuous fluorescence measurement), and finally a cooling step to $4^{\circ} \mathrm{C}$. Product purity, product size, and absence of primer dimers were confirmed by DNA melting curve analysis. Melt curves yielded a single sharp peak for all template reactions, and a minimal melt peak (resulting from primer dimers) or no melt peaks for the no-template control reactions.

Statistics. We performed the Hardy-Weinberg exact test to analyze deviations from equilibrium and association analysis to evaluate genetic effects on phenotype using the statistical software R (www.R-project.org). Single nucleotide polymorphisms (SNPs) whose genotype frequencies departed from Hardy-Weinberg equilibrium at $\mathrm{p}<0.01$ were filtered out. Thus, we evaluated associations among the 3 promoter SNPs rs11730582, rs2728127 and rs29001511 in the promoter region with various breast cancer characteristics. These statistical evaluations were carried out using multivariate logistic regression under an additive genetic model by $\chi^{2}$ test. The accepted significance level for association analysis was 0.1 .

The case-control haplotype analysis was performed using Haploview v4.2 (http://www.broad.mit.edu/mpg/haploview). Similar to the association analysis, the 3 SNPs, rs11730582, rs2728127 and rs29001511 in the promoter region, were used to generate haplotype frequencies, as the genotype data for these SNPs had a p-value above the cut-off value of 0.01 .

\section{Results}

Patient demographics. This study comprised 241 breast cancer specimens, for which DNA from normal surrounding tissue was available for 111 , and 65 healthy breast samples. The entire cohort consisted exclusively of women. In all groups, the mean age was close to 50 years. The demographic and cancer characteristics are specified in Table I.

Individual polymorphic sites and cancer. The polymorphic site in position -66 was not in Hardy-Weinberg equilibrium and hence was not included in further analyses. When comparing the other 3 promoter SNPs between cancers and healthy controls, the association analysis by $\chi^{2}$ test using multivariate logistic regression under an additive genetic model did not reveal significant differences between the groups for positions $-443,-1748$ or -1776 . However, a separate analysis using the Cochran-Armitage trend test (CATT) and assuming a reces- 
Table I. Patient demographics.

\begin{tabular}{|c|c|c|c|}
\hline Characteristics & Breast cancer $(241)$ & Normal surrounding tissue (111) & Normal breasts (71) \\
\hline \multicolumn{4}{|l|}{ Cancer subtypes } \\
\hline Ductal & 212 & 98 & 0 \\
\hline Lobular & 13 & 7 & 0 \\
\hline Mucinous & 2 & 2 & 0 \\
\hline Papillary & 0 & 0 & 0 \\
\hline Age (years) (means \pm SEM) & $52.22 \pm 0.79$ & $50.71 \pm 0.97$ & $49.13 \pm 1.60$ \\
\hline \multicolumn{4}{|l|}{ Race } \\
\hline Caucasian & 85 & 49 & 53 \\
\hline Asian & 87 & 51 & 1 \\
\hline Black & 17 & 3 & 7 \\
\hline Hispanic & 0 & 0 & 0 \\
\hline Middle Eastern & 0 & 0 & 1 \\
\hline Tumor size & $1.9 \pm 1.1$ & $1.9 \pm 1.1$ & na \\
\hline \multicolumn{4}{|l|}{ Tumor grade } \\
\hline 1 & 13 & 6 & na \\
\hline 2 & 63 & 34 & na \\
\hline 3 & 70 & 19 & na \\
\hline \multicolumn{4}{|l|}{ Tumor stage } \\
\hline $\mathrm{T} 1$ & 76 & 43 & na \\
\hline $\mathrm{T} 2$ & 114 & 50 & na \\
\hline $\mathrm{T} 3$ & 24 & 7 & na \\
\hline $\mathrm{T} 4$ & 7 & 2 & na \\
\hline No & 90 & 44 & na \\
\hline N1 & 87 & 42 & na \\
\hline N2 & 11 & 4 & na \\
\hline N3 & 24 & 12 & na \\
\hline N4 & 1 & 0 & na \\
\hline M0 & 89 & 51 & na \\
\hline M1 & 1 & 0 & na \\
\hline \multicolumn{4}{|l|}{ Tumor stage } \\
\hline I & 42 & 22 & na \\
\hline II & 130 & 60 & na \\
\hline III & 52 & 20 & na \\
\hline IV & 1 & 0 & na \\
\hline \multicolumn{4}{|l|}{ ER status } \\
\hline+ & 98 & 47 & na \\
\hline- & 79 & 33 & na \\
\hline \multicolumn{4}{|l|}{ PR status } \\
\hline+ & 94 & 42 & na \\
\hline- & 85 & 38 & na \\
\hline \multicolumn{4}{|l|}{ HER2 status } \\
\hline+ & 54 & 18 & na \\
\hline- & 84 & 36 & na \\
\hline
\end{tabular}

ER, estrogen receptor; PR, progesterone receptor; na, not applicable.

sive genetic model reached accepted levels of significance for all three sites, implying the possibility of a weak association of these polymorphisms with cancer. A small set of DNAs from colon samples showed a distribution of SNPs very similar to breast cancer (Fig. 2A). For studying the coding region polymorphisms that are associated with amino acid changes, 4 probes were available. At SNP position 305, 3 tumors had a deviant genotype from all other specimens. This SNP was 
A

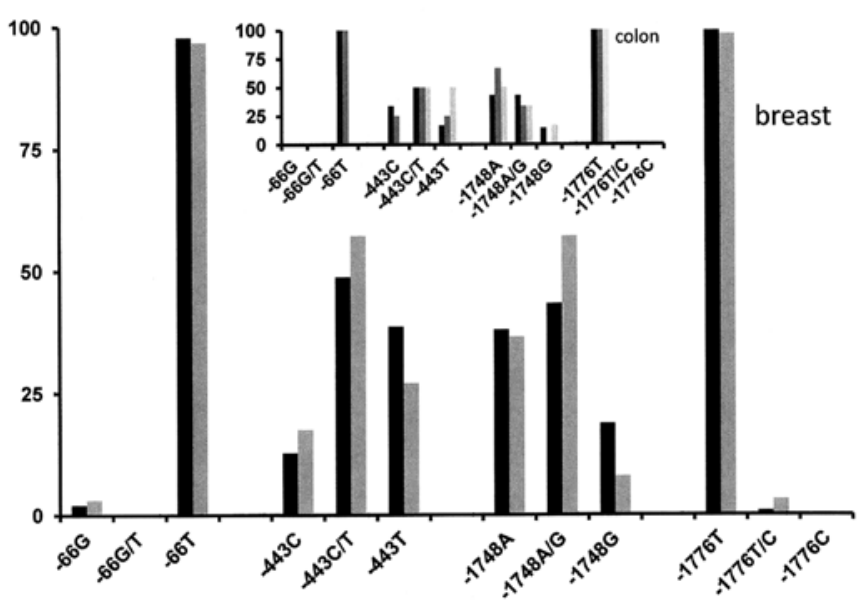

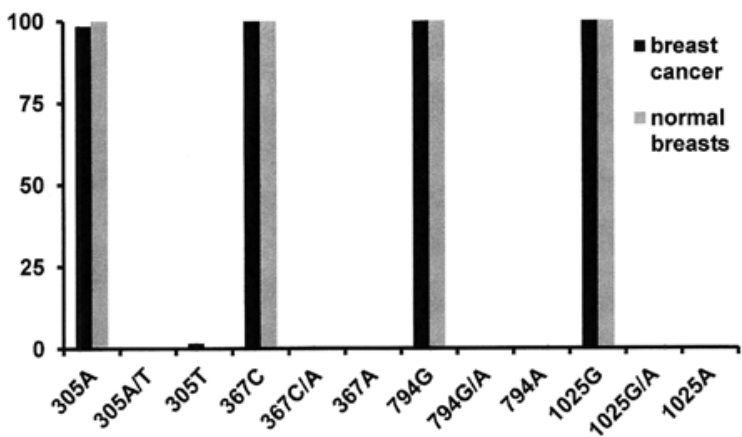

Figure 2. Allelic distribution in breast cancer. (A) Comparison of promoter polymorphisms in breast cancer ( $\mathrm{n}=236)$ vs. healthy controls $(\mathrm{n}=63)$ ( $\mathrm{y}$-axis is percentage of the total). [Insert, for comparison, a small number of colon specimens ( 7 colorectal cancers-black, 4 surrounding tissues-dark gray, 5 benign growths and non-tumor disease-light gray) with a similar distribution is shown. The samples were obtained from the University of Cincinnati tissue procurement]. (B) Coding region non-synonymous polymorphic sites in breast cancer $(\mathrm{n}=210)$ and healthy controls $(\mathrm{n}=24)$.

A
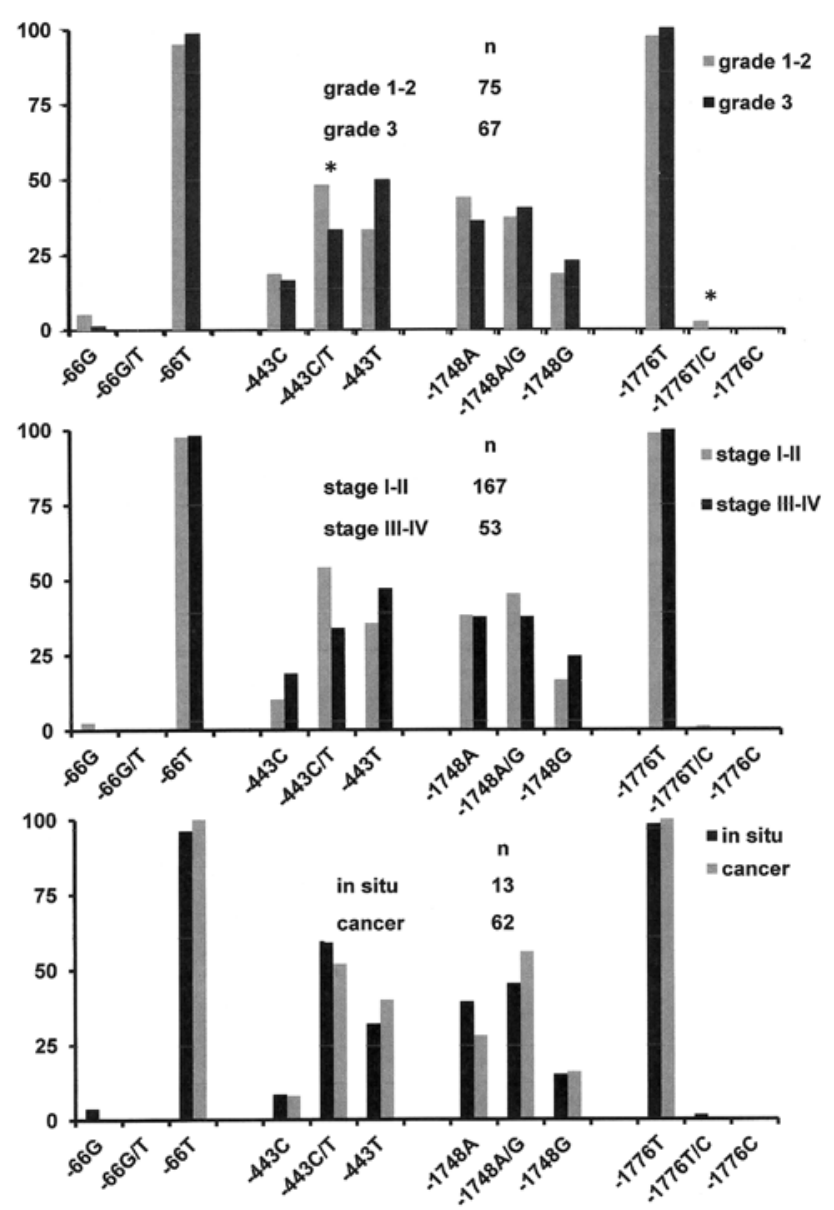

B
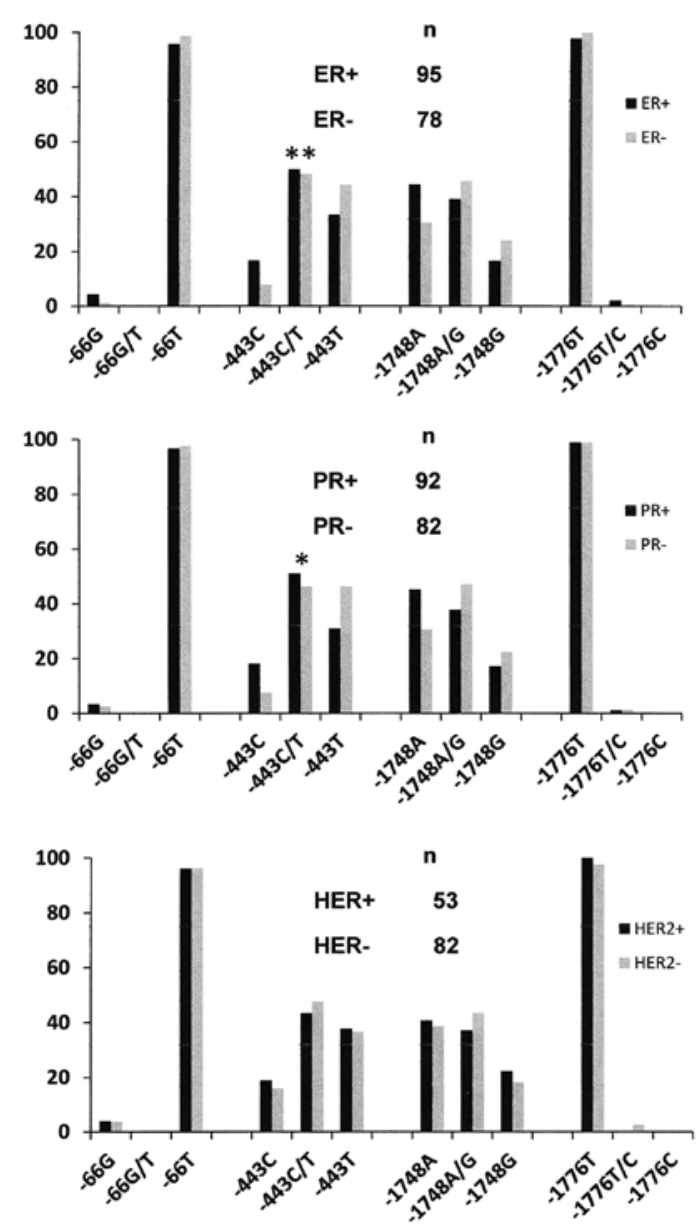

Figure 3. Allelic distribution and cancer characteristics. (A) The top panel indicates promoter polymorphisms related to cancer grade (percent of total), the middle panel shows the relation to cancer stage, and the bottom panel reflects the comparison of in situ carcinomas vs. cancer. (B) Osteopontin promoter polymorphisms in relation to ER expression (top panel), PR expression (middle panel), or HER2 expression (bottom panel) of the cancers. *Significant difference between groups at $\mathrm{p}<0.1{ }^{*}$, significant difference between groups at $\mathrm{p}<0.05$. ER, estrogen receptor; PR, progesterone receptor.

in Hardy-Weinberg dysequilibrium. The polymorphic sites in positions 367, 794 and 1025 showed one homozygous genotype for all specimens in this study and therefore were not further analyzed (Fig. 2B). 

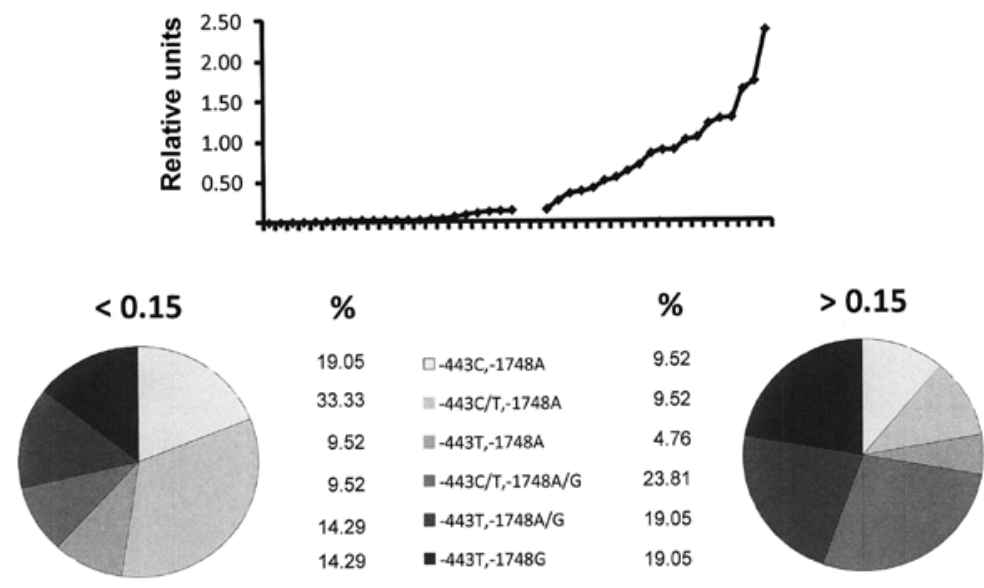

Figure 4. Influence of spp1 promoter haplotype on osteopontin mRNA expression. The samples from cancer patients and healthy controls were combined and then divided into 2 groups of low $(<0.15$ relative units, $\mathrm{n}=21)$ or high $(>0.15$ relative units, $\mathrm{n}=18)$ expression levels. Top panel: Distribution of osteopontin expression levels and population cut-off. Bottom panel: As all had the genotype T/T in positions -66 and -1776, the expression level was correlated to the haplotypes generated in positions -443 and -1748 .

\section{cancer}

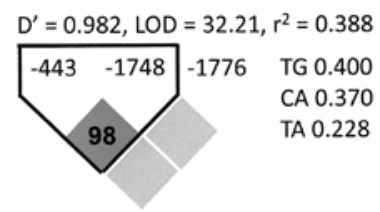

Figure 5. Promoter haplotype. Haplotype associations were tested for the 4 polymorphic sites under study. The SNP in position -66 was not in Hardy-Weinberg equilibrium and was excluded. In both breast cancer patients and controls there was an association between SNPs -443 and -1748 , while no associations were found for SNP -1776. D', normalized linkage disequilibrium coefficient between pairs of loci; LOD, log of the odds score (measure for probability of a linkage relationship among selected loci); $\mathrm{r}^{2}$, squared correlation coefficient between 2 SNPs. SNPs, single nucleotide polymorphisms.

Individual polymorphic sites and clinical measures of cancer. Within the cancer cohort, the polymorphisms in position -443 was correlated with tumor grade (after combining grades 1 plus 2 and comparing them to grade 3 ). The difference in position -443 between low grade and high grade cancers was confirmed by reanalysis with an allelic based test, with a recessive genetic model, and an additive/multiplicative genetic model using CATT. The polymorphic site in position -1776 just barely reached a level of significance when grades 1 and 2 were combined (grade 1 alone contained only 13 tumor samples) and compared to grade 3 . However a reanalysis of grade 1 vs. grade 2 and grade 2 vs. grade 3 did not reflect significant differences in genotype at this position. There was no association between the promoter SNPs and tumor stage (I-II vs. III-IV) or in situ carcinoma vs. cancer (Fig. 3A). The latter results were expected as stage and early transformation are determined by the sampling time more than by tumor genetics.

Osteopontin expression has been associated with breast cancer progression, regardless of the histologic subtype of the cancer $(4,6)$. Importantly, the polymorphic site at -443 , but not -1748 or -1776 , showed differences between ER-positive and ER-negative breast cancers and between
PR-positive and PR-negative breast cancers, but there was no association with HER2 status. The -443 allele $T$ was more common in the ER-negative cancers and in the PR-negative cancers (Fig. 3B).

Somatic mutations. For 111 cancers, DNA from the matching untransformed surrounding tissues was available. We tested it to detect possible somatic mutations. None were found in position -66. In position -443, 2 tumors were heterozygous in homozygous hosts, one with the $\mathrm{C} / \mathrm{C}$ genotype and the other with the T/T genotype. In position $-1748,2$ tumors had a heterozygous genotype, altered from the host homozygous A/A. In position -1776, 1 tumor was heterozygous in a homozygous $\mathrm{T} / \mathrm{T}$ host. These results suggest that tumors may encounter somatic mutations in the spp1 promoter that have the potential to affect expression levels. For the coding region polymorphic sites (positions 305, 367, 794 and 1025), there were no differences between tumor and untransformed surrounding tissue.

Associations of polymorphisms and expression levels. For a subset of samples, information was available concerning the expression levels of osteopontin according to real-time RT-PCR analysis from breast tissue. We questioned whether the promoter haplotype was correlated with expression, using 0.15 relative units as the cut-off between high and low osteopontin expression. As the allelic distribution in positions -66 and -1776 was almost homogeneous in patients as well as in the normal controls, we focused on -443 and -1748 . The base $\mathrm{G}$ in position -1748 , on a homozygous or heterozygous background, was associated with higher expression levels of osteopontin RNA in the breast tissue $(74 \% \mathrm{G}$ in high expressors vs. $41 \% \mathrm{G}$ in low expressors) (Fig. 4). Of the 6 tumors with the highest osteopontin expression ( $>1.2$ relative units), 4 had a $\mathrm{G}$ in position -1748 . The polymorphic site in position -443 appeared to have a lesser effect, but the fraction of $\mathrm{T} / \mathrm{T}$ was increased and the fraction of $\mathrm{C} / \mathrm{C}$ was decreased in the population of high expressors compared to the low expressors $(47 \% \mathrm{~T} / \mathrm{T}$ in high expressors vs. $38 \% \mathrm{~T} / \mathrm{T}$ in low expressors). 
Table II. Frequencies of the polymorphisms.

\begin{tabular}{|c|c|c|c|c|c|c|c|}
\hline Position & rs number & Alleles & HapMap ratio & ABI ratio & NCBI SNP ratio & MAF & $\begin{array}{c}\text { Present } \\
\text { study ratio }\end{array}$ \\
\hline-1776 & rs29001511 & $\mathrm{C} / \mathrm{T}$ & $0.017 / 0.983$ & $\begin{array}{l}0.03 / 0.97 \text { (Cauc) } \\
0.00 / 1.00 \text { (Black) }\end{array}$ & $0.017 / 0.983$ & $\mathrm{C}=0.0059 / 13$ & $0.007 / 0.993$ \\
\hline-1748 & rs2728127 & $\mathrm{A} / \mathrm{G}$ & $0.5 / 0.5$ & $\begin{array}{l}0.66 / 0.34 \text { (Cauc) } \\
0.53 / 0.47 \text { (Black) }\end{array}$ & $0.624 / 0.376$ & $\mathrm{G}=0.3679 / 805$ & $0.626 / 0.374$ \\
\hline-443 & rs11730582 & $\mathrm{C} / \mathrm{T}$ & $0.26 / 0.74$ & $\begin{array}{l}0.44 / 0.56 \text { (Cauc) } \\
0.14 / 0.86 \text { (Black) } \\
0.305 / 0.695 \text { (Asian) }\end{array}$ & $0.300 / 0.700$ & $\mathrm{C}=0.3419 / 748$ & $0.404 / 0.596$ \\
\hline-66 & rs28357094 & $\mathrm{G} / \mathrm{T}$ & $0.5 / 0.5$ & $\begin{array}{l}0.26 / 0.74 \text { (Cauc) } \\
0.09 / 0.91 \text { (Black) }\end{array}$ & $0.170 / 0.830$ & $\mathrm{G}=0.1175 / 257$ & $0.036 / 0.964$ \\
\hline 305 & rs11544546 & $\mathrm{A} / \mathrm{T}$ & - & - & - & - & $0.98 / 0.02$ \\
\hline 367 & rs11544549 & $\mathrm{C} / \mathrm{A}$ & - & - & - & - & $1.00 / 0.00$ \\
\hline 794 & rs7435825 & $\mathrm{G} / \mathrm{A}$ & $\begin{array}{l}1.00 / 0.00 \text { (Cauc) } \\
0.81 / 0.19 \text { (Black) } \\
1.00 / 0.00 \text { (Asian) }\end{array}$ & $\begin{array}{l}1.00 / 0.00 \text { (Cauc) } \\
0.88 / 0.14 \text { (Black) }\end{array}$ & $1.00 / 0.00$ & $A=0.043 / 94$ & $1.00 / 0.00$ \\
\hline 1025 & rs4660 & $\mathrm{G} / \mathrm{A}$ & $\begin{array}{l}1.00 / 0.00 \text { (Cauc) } \\
0.90 / 0.10 \text { (Black) } \\
1.00 / 0.00 \text { (Asian) }\end{array}$ & $\begin{array}{l}1.00 / 0.00 \text { (Cauc) } \\
0.88 / 0.12 \text { (Black) }\end{array}$ & $0.951 / 0.049$ & $A=0.017 / 38$ & $1.00 / 0.00$ \\
\hline
\end{tabular}

Reported polymorphism frequencies from multiple sources are compared to the distributions obtained in the present study. In ABI, Asians are the average of Japanese and Chinese. For the NCBI SNP, the ratios reflect all studies combined (weighted averages). The present study includes the average of all samples, including cancers, surrounding tissue and healthy controls. SNP, single nucleotide polymorphism; MAF, minor allele frequency; Cauc, Caucasian.

Table III. Functions of the polymorphic sites in the spp1 promoter.

\begin{tabular}{|c|c|c|c|}
\hline Position & Transcription factor & Disease & Refs. \\
\hline-66 & SP1/SP3 & $\begin{array}{l}\text { Duchenne muscular dystrophy } \\
\text { Osteoarthritis } \\
\text { Atherosclerosis predisposition } \\
\text { Type } 1 \text { diabetes }\end{array}$ & $\begin{array}{c}(32) \\
(25) \\
(33) \\
(15,16,34)\end{array}$ \\
\hline$-145 /-146$ & & Nephrolithiasis & (28) \\
\hline-156 & RUNX2 & $\begin{array}{l}\text { Glioma } \\
\text { Pseudoxanthoma elasticum } \\
\text { Systemic lupus erythematosus } \\
\text { Systemic sclerosis } \\
\text { Diastolic dysfunction in hypertension }\end{array}$ & $\begin{array}{c}(15) \\
(31) \\
(35,36) \\
(37) \\
(38)\end{array}$ \\
\hline-443 & MYB & $\begin{array}{l}\text { Hepatitis c } \\
\text { Melanoma } \\
\text { Gastric cancer } \\
\text { Diabetic nephropathy } \\
\text { Thrombocytopenia, anemia in SLE } \\
\text { Myocardial infarction } \\
\text { Osteoarthritis }\end{array}$ & $\begin{array}{l}(21,22) \\
(18) \\
(19) \\
(23) \\
(24) \\
(30) \\
(25)\end{array}$ \\
\hline-593 & & Nephrolithiasis & (29) \\
\hline-1748 & & Pseudoxanthoma elasticum & $(31)$ \\
\hline
\end{tabular}

For the polymorphic sites at positions $-66,-156,-443,-593$, and -1748 , disease associations, and in some cases cognate transcription factors have been identified in the literature. 
Haplotype analysis. We performed a haplotype analysis for the promoter SNPs. The polymorphic site in position -66 was eliminated from this evaluation as it was not in Hardy-Weinberg equilibrium. Among the other three sites, there was an association between -443 and -1748 in the cancer patient group as well as in the healthy controls. No association was found for SNP -1776 with either of the other polymorphic sites (Fig. 5).

\section{Discussion}

Certain cancer-associated mutations may be individually transforming, such as the chromosome translocation that generates the chimeric kinase BCR-ABL in CML or the loss-of-function mutations of $\mathrm{RB}$ that cause retinoblastoma. Other mutations or polymorphisms have the nature of quantitative trait loci that collectively affect the risk for transformation or progression, with each individual site contributing only moderately. It is safe to assume that many of the cancer-associated genetic changes in the latter category have not been identified.

The spp1 gene, which encodes osteopontin, is located on chromosome $4 \mathrm{q} 22.1$. The very diverse roles of the gene product in physiology and pathophysiology are regulated on the post-transcriptional level (glycosylation, phosphorylation, sulfation, calcium binding, heparin binding, proteolysis, transglutamination), in RNA processing (3 alternative splice variants, alternative translation from a non-canonical start site), and genetically (polymorphisms in coding and non-coding regions). Since $2004(15,16)$, there has been increasing interest in the biological roles for spp1 promoter polymorphisms in various pathologies. Here, we report that promoter polymorphisms are also relevant for breast cancer.

Abundant production of osteopontin is correlated with aggressiveness (higher stage, higher grade and early progression) in multiple forms of cancer (3). Known mechanisms for osteopontin induction in cancer include the activation of gene expression due to elevated signal transduction and the alternative splicing of the spp1 transcript. It was possible that high expression polymorphisms in the spp1 promoter may also contribute to an elevated risk for tumor aggressiveness. Here, we tested this hypothesis. We found the polymorphic site in position -443 of the promoter to be associated with tumor grade, such that the allele $\mathrm{T}$ is more common in high grade tumors. It is also more common in high expressors of osteopontin compared to low expressors. Furthermore, this allele occurs at a higher frequency in cancers that lack ER over cancers that express this receptor and in cancers that lack PR over those that express PR. We found that $\mathrm{T}$ in position -443 was associated with higher aggressiveness of cancers, and consistently hormone receptornegative cancers tend to grow more rapidly and have a worse prognosis than breast tumors that express ER or PR.

To assess our results against the existing base of knowledge, we compared this study to the distribution of polymorphic site frequencies according to public databases (Table II). The polymorphism in position -443 has been associated with various disease phenotypes (Table III). A DNA sequence similar to a c-MYB core binding motif, CAGTT, immediately precedes the -443 polymorphic promoter position CAAGTT(C/T). However, the canonical c-MYB site is 5'-(T/C)AAC(G/T)G-3' (17), and transcription via c-MYB from the non-canonical site in the sppl promoter may be context-dependent. While c-MYB causes higher transcription from the $\mathrm{C}$ allele, there is evidence that under some circumstances the $\mathrm{T}$ allele may be associated with higher levels of expression. In melanoma and gastric cancer, the -443 allele $\mathrm{C}$ may have elevated transcription over allele $\mathrm{T}$ or heterozygous $\mathrm{C} / \mathrm{T}$, causing an increased risk for tumor progression and reduced survival rates $(18,19)$. In hepatitis $\mathrm{C}$, the $\mathrm{T} / \mathrm{T}$ genotype has been associated with an increased anti-viral response to hepatitis $\mathrm{C}$ [which requires high levels of osteopontin (20)], however, the T allele may be more common in patients with high hepatitis activity (reflective of a compromised antiviral response due to low levels of osteopontin secretion) $(21,22)$. In diseases with autoimmune components, the published results likewise point to a complex role for the SNP in position -443. Nephropathy in diabetes is more common in carriers of the $\mathrm{T}$ allele (23), which may reflect increased inflammation due to high osteopontin expression. Conversely, thrombocytopenia and hemolytic anemia in lupus have an autoantibody-mediated pathogenesis, which is supported by osteopontin, more strongly in carriers of the $\mathrm{C}$ allele (24). The polymorphic site -443 is associated with osteoarthritis risk and severity. Thrombin-cleaved osteopontin levels in the synovial fluid are lower in subjects with the $-443 \mathrm{~T} / \mathrm{T}$ genotype, resulting in milder disease (25). In the present study the $\mathrm{T}$ allele was represented more frequently than the $\mathrm{C}$ allele at high tumor grade and in tumors with high osteopontin RNA levels (of note, for a subset of samples this result was confirmed by reanalysis in an external core facility to exclude the possibility of an erroneous data set). This implies an important role for c-MYBindependent osteopontin expression in breast cancer.

The SNP frequency in the osteopontin promoter (Fig. 1A) was roughly consistent with the estimated variability in DNA sequence among humans which is $0.3 \%$. Notably, the coding region polymorphisms reported in the NCBI SNP database was disproportionately higher. This is consistent with the low evolutionary preservation of the osteopontin protein sequence and with the low structural constraints of the molecule. It may reflect an unstable chromosome locus. However, few of the deposited SNPs are backed by larger population studies and those located in critical functional sites (such as mutations of the RGD motif) may be exceedingly rare. In this study, we assessed only non-synonymous (i.e. amino acid-changing) polymorphic sites, for which probes were available. The study population was entirely homozygous for 3 of the 4 . Further investigation is required to assess the potential roles of coding region polymorphisms within the spp1 gene in breast cancer. 56 of our specimens were assessed with 2-6-fold coverage. For most of them, the reproducibility was $100 \%$. Few samples with lower quality DNA had reproducibility in 4 of 6 repeats.

\section{Acknowledgements}

This research was supported by DOD grants BC095225 and PR094070 to G.F.W. Patient samples were obtained under IRB protocol 04-01-29-01 from the University of Cincinnati.

\section{References}

1. Weber GF and Ashkar S: Stress response genes: the genes that make cancer metastasize. J Mol Med 78: 404-408, 2000.

2. Weber GF: Molecular mechanisms of metastasis. Cancer Lett 270: 181-190, 2008. 
3. Weber GF, Lett S and Haubein N: Osteopontin is a marker for cancer aggressiveness and patient survival. Br J Cancer 103: 861-869, 2010.

4. Weber GF, Lett GS and Haubein NC: Categorical meta-analysis of osteopontin as a clinical cancer marker. Oncol Rep 25: 433-441, 2011.

5. Weber GF: The cancer biomarker osteopontin: combination with other markers. Cancer Genomics Proteomics 8: 263-288, 2011.

6. Mirza M, Shaughnessy E, Hurley JK, Vanpatten KA, Pestano GA, $\mathrm{He} \mathrm{B}$ and Weber GF: Osteopontin-c is a selective marker for breast cancer. Int J Cancer 122: 889-897, 2008.

7. Sullivan J, Blair L, Alnajar A, Aziz T, Ng CY, Chipitsyna G, Gong Q, Witkiewicz A, Weber GF, Denhardt DT, Yeo CJ and Arafat HA: Expression of a prometastatic splice variant of osteopontin, OPNC, in human pancreatic ductal adenocarcinoma. Surgery 146: 232-240, 2009.

8. Tilli TM, Franco VF, Robbs BK, Wanderley JL, da Silva FR, de Mello KD, Viola JP, Weber GF and Gimba ER: Osteopontin-c splicing isoform contributes to ovarian cancer progression. Mol Cancer Res 9: 280-293, 2011.

9. He B, Mirza M and Weber GF: An osteopontin splice variant induces anchorage independence in human breast cancer cells. Oncogene 25: 2192-2202, 2006.

10. Senger DR, Asch BB, Smith BD, Perruzzi CA and Dvorak HF: A secreted phosphoprotein marker for neoplastic transformation of both epithelial and fibroblastic cells. Nature 302: 714-715, 1983.

11. Noda M, Yoon K, Prince CW, Butler WT and Rodan GA Transcriptional regulation of osteopontin production in rat osteosarcoma cells by type $\beta$ transforming growth factor. J Bio Chem 263: 13916-13921, 1988

12. Chambers AF, Behrend EI, Wilson SM and Denhardt DT: Induction of expression of osteopontin (OPN; secreted phosphoprotein) in metastatic, ras-transformed NIH $3 \mathrm{~T} 3$ cells. Anticancer Res 12: 43-47, 1992.

13. Zhang G, He B and Weber GF: Growth factor signaling induces metastasis genes in transformed cells: molecular connection between Akt kinase and osteopontin in breast cancer. Mol Cell Biol 23: 6507-6519, 2003

14. Whalen KA, Weber GF, Benjamin TL and Schaffhausen BS: Polyomavirus middle $\mathrm{T}$ antigen induces the transcription of osteopontin, a gene important for migration of transformed cells. J Virol 82: 4946-4954, 2008.

15. Giacopelli F, Marciano R, Pistorio A, Catarsi P, Canini S, Karsenty G and Ravazzolo R: Polymorphisms in the osteopontin promoter affect its transcriptional activity. Physiol Genomics 20: $87-96,2004$

16. Hummelshoj T, Ryder LP, Madsen HO, Odum N and Svejgaard A A functional polymorphism in the Eta-1 promoter is associated with allele specific binding to the transcription factor $\mathrm{Sp} 1$ and elevated gene expression. Mol Immunol 43: 980-986, 2006.

17. Deng QL, Ishii S and Sarai A: Binding site analysis of c-Myb: screening of potential binding sites by using the mutation matrix derived from systematic binding affinity measurements. Nucleic Acids Res 24: 766-774, 1996.

18. Schultz J, Lorenz P, Ibrahim SM, Kundt G, Gross G and Kunz M The functional $-443 \mathrm{~T} / \mathrm{C}$ osteopontin promoter polymorphism influences osteopontin gene expression in melanoma cells via binding of c-Myb transcription factor. Mol Carcinog 48: 14-23, 2009

19. Zhao F, Chen X, Meng T, Hao B, Zhang Z and Zhang G: Genetic polymorphisms in the osteopontin promoter increases the risk of distance metastasis and death in Chinese patients with gastric cancer. BMC Cancer 12: 477, 2012.

20. Ashkar S, Weber GF, Panoutsakopoulou V, Sanchirico ME Janssen M, Zawaideh S, Rittling S, Denhardt DT, Glimcher MJ and Cantor H: Eta-1 (osteopontin): an early component of type-1 (cell-mediated) immunity. Science 287: 860-864, 2000.

21. Shaker OG, Sadik NA and El-Dessouki A: Single-nucleotide polymorphism in the promoter region of the osteopontin gene at nucleotide -443 as a marker predicting the efficacy of pegylated interferon/ribavirin-therapy in Egyptians patients with chronic hepatitis C. Hum Immunol 73: 1039-1045, 2012.

22. Mochida S, Hashimoto M, Matsui A, Naito M, Inao M, Nagoshi S, Nagano M, Egashira T, Mishiro S and Fujiwara K: Genetic polymorphisms in promoter region of osteopontin gene may be a marker reflecting hepatitis activity in chronic hepatitis C patients. Biochem Biophys Res Commun 313: 1079-1085, 2004
23. Cheema BS, Iyengar S, Ahluwalia TS, Kohli HS, Sharma R, Shah VN, Bhansali A, Sakhuja V and Khullar M: Association of an Osteopontin gene promoter polymorphism with susceptibility to diabetic nephropathy in Asian Indians. Clin Chim Acta 413 1600-1604, 2012

24. Trivedi T, Franek BS, Green SL, Kariuki SN, Kumabe M, Mikolaitis RA, Jolly M, Utset TO and Niewold TB: Osteopontin alleles are associated with clinical characteristics in systemic lupus erythematosus. J Biomed Biotechnol 2011: 802581, 2011.

25. Jiang Y, Yao M, Liu Q and Zhou C: OPN gene polymorphisms influence the risk of knee OA and OPN levels in synovial fluid in a Chinese population. Arthritis Res Ther 15: R3, 2013.

26. Naito $M$, Matsui $A$, Inao $M$, Nagoshi $S$, Nagano $M$, Ito $N$, Egashira T, Hashimoto M, Mishiro S, Mochida S and Fujiwara K: SNPs in the promoter region of the osteopontin gene as a marker predicting the efficacy of interferon-based therapies in patients with chronic hepatitis C. J Gastroenterol 40: 381-388, 2005.

27. Xu G, Sun W, He D, Wang L, Zheng W, Nie H, Ni L, Zhang D, Li $\mathrm{N}$ and Zhang J: Overexpression of osteopontin in rheumatoid synovial mononuclear cells is associated with joint inflammation, not with genetic polymorphism. J Rheumatol 32: 410-416, 2005.

28. Gao B, Yasui T, Itoh Y, Li Z, Okada A, Tozawa K, Hayashi Y and Kohri K: Association of osteopontin gene haplotypes with nephrolithiasis. Kidney Int 72: 592-598, 2007.

29. Gögebakan B, Igci YZ, Arslan A, Igci M, Erturhan S, Oztuzcu S, Sen H, Demiryürek S, Arikoglu H, Cengiz B, Bayraktar R, Yurtseven C, Sarıca K and Demiryürek AT: Association between the T-593A and C6982T polymorphisms of the osteopontin gene and risk of developing nephrolithiasis. Arch Med Res 41: 442-448, 2010.

30. Schmidt-Petersen K, Brand E, Telgmann R, Nicaud V,Hagedorn C, Labreuche J, Dördelmann C, Elbaz A, Gautier-Bertrand M, Fischer JW, Evans A, Morrison C, Arveiler D, Stoll M, Amarenco P, Cambien F, Paul M and Brand-Herrmann SM: Osteopontin gene variation and cardio/cerebrovascular disease phenotypes. Atherosclerosis 206: 209-215, 2009.

31. Hendig D, Arndt M, Szliska C, Kleesiek K and Götting C: SPPI promoter polymorphisms: identification of the first modifier gene for pseudoxanthoma elasticum. Clin Chem 53: 829-836, 2007.

32. Pegoraro E, Hoffman EP, Piva L, Gavassini BF, Cagnin S, Ermani M, Bello L, Soraru G, Pacchioni B, Bonifati MD, Lanfranchi G, Angelini C, Kesari A, Lee I, Gordish-Dressman H, Devaney JM, McDonald CM; Cooperative International Neuromuscular Research Group: SPP1 genotype is a determinant of disease severity in Duchenne muscular dystrophy. Neurology 76: 219-226, 2011.

33. de las Fuentes L, Gu CC, Mathews SJ, Reagan JL, Ruthmann NP, Waggoner AD, Lai CF, Towler DA and Dávila-Román VG: Osteopontin promoter polymorphism is associated with increased carotid intima-media thickness. J Am Soc Echocardiogr 21: 954-960, 2008

34. Marciano R, D'Annunzio G, Minuto N, Pasquali L, Santamaria A, Di Duca M, Ravazzolo R and Lorini R: Association of alleles at polymorphic sites in the osteopontin encoding gene in young type 1 diabetic patients. Clin Immunol 131: 84-91, 2009.

35. D'Alfonso S, Barizzone N, Giordano M, Chiocchetti A, Magnani C, Castelli L, Indelicato M, Giacopelli F, Marchini M, Scorza R, Danieli MG, Cappelli M, Migliaresi S, Bigliardo B, Sabbadini MG, Baldissera E, Galeazzi M, Sebastiani GD, Minisola G, Ravazzolo R, Dianzani U and Momigliano-Richiardi P: Two single-nucleotide polymorphisms in the 5' and 3 ' ends of the osteopontin gene contribute to susceptibility to systemic lupus erythematosus. Arthritis Rheum 52: 539-547, 2005.

36. Chen J, Wu Q, Lu Y, Xu T, Huang Y, Ribas J, Ni X, Hu G, Huang F, Zhou L and Lu D: SPP1 promoter polymorphisms and glioma risk in a Chinese Han population. J Hum Genet 55: 456-461, 2010.

37. Barizzone N, Marchini M, Cappiello F, Chiocchetti A, Orilieri E, Ferrante D, Corrado L, Mellone S, Scorza R, Dianzani U and D'Alfonso S: Association of osteopontin regulatory polymorphisms with systemic sclerosis. Hum Immunol 72: 930-934, 2011.

38. Nakayama H, Nagai H, Matsumoto K, Oguro R, Sugimoto K, Kamide K, Ohishi M, Katsuya T, Okamoto H, Maeda M, Komamura K, Azuma J, Rakugi H and Fujio Y: Association between osteopontin promoter variants and diastolic dysfunction in hypertensive heart in the Japanese population. Hypertens Res 34: 1141-1146, 2011 